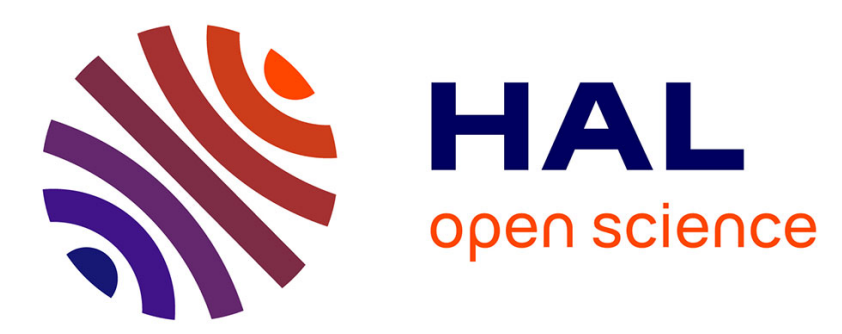

\title{
Effects and interactions of temperature and stress-level related damage on permeability of concrete
}

\author{
Marta Choinska, Abdelhafid Khelidj, Georges Chatzigeorgiou, Gilles
}

Pijaudier-Cabot

\section{- To cite this version:}

Marta Choinska, Abdelhafid Khelidj, Georges Chatzigeorgiou, Gilles Pijaudier-Cabot. Effects and interactions of temperature and stress-level related damage on permeability of concrete. Cement and Concrete Research, 2007, 37 (1), pp.79-88. 10.1016/j.cemconres.2006.09.015 . hal-00354323

\section{HAL Id: hal-00354323 \\ https://hal.science/hal-00354323}

Submitted on 27 Jul 2017

HAL is a multi-disciplinary open access archive for the deposit and dissemination of scientific research documents, whether they are published or not. The documents may come from teaching and research institutions in France or abroad, or from public or private research centers.
L'archive ouverte pluridisciplinaire HAL, est destinée au dépôt et à la diffusion de documents scientifiques de niveau recherche, publiés ou non, émanant des établissements d'enseignement et de recherche français ou étrangers, des laboratoires publics ou privés.

\section{(c)(1)}

Distributed under a Creative Commons Attribution| 4.0 International License 


\title{
Effects and interactions of temperature and stress-level related damage on permeability of concrete
}

\author{
Marta Choinska $^{\mathrm{a}}$, Abdelhafid Khelidj ${ }^{\mathrm{b}}$, George Chatzigeorgiou ${ }^{\mathrm{c}}$, Gilles Pijaudier-Cabot ${ }^{\mathrm{a}}$ \\ ${ }^{\mathrm{a}}$ R\&DO, Institut GeM / UMR CNRS 6183, Ecole Centrale de Nantes, 1 rue de la Noë, BP 92101, 44321 Nantes Cedex 3, France \\ ${ }^{\mathrm{b}}$ R\&DO, Institut GeM / UMR CNRS 6183, I.U.T. de Saint Nazaire, dépt. Génie Civil, BP 420 Heinlex, 44600 Saint Nazaire, France \\ ${ }^{c}$ Department of Civil Engineering, Division of Structures, University Campus, Aristotle University of Thessaloniki, 54006 Thessaloniki, Greece
}

The objective of this study is to investigate damage-temperature-stress level-permeability interactions in structural concrete. The tests are performed on hollow cylindrical concrete specimens, subjected to compressive loading and temperature up to $150{ }^{\circ} \mathrm{C}$. The results emphasize that at stress levels lower than $80 \%$ of the peak stress, the variation of permeability is small and it is slightly influenced by the stress. As a matter of fact, the permeability under load is smaller than the permeability measured after unloading. As the load exceeds $80 \%$ of the peak stress, microcracking increases rapidly, causing an increase of the permeability and a greater sensitivity to the applied load, i.e. a noticeable difference between the permeability measured under load and after unloading, the first becoming greater than the latter. In the post-peak phase the increase of permeability is much larger due to significant crack width growth. The increase of permeability with the applied load seems to be greater with temperature, inducing further alterations of concrete and dilation of the porous structure of the material. Finally, the experimental results seem to agree with the format of coupled evolution of the permeability due to damage and temperature assumed by Gawin et al. [D. Gawin, C.E. Majorana, B.A. Schrefler, Numerical analysis of hygro-thermal behaviour and damage of concrete at high temperature, Mechanics of Cohesive-Frictional Materials 4 (1999) 37-74.].

Keywords: Concrete; Permeability; Cracking; Damage; Temperature

\section{Introduction}

The permeability of concrete measures the ability of this porous material to transfer fluids under a gradient of pressure. The fluid flow occurs in a porous network, which comprises both the initial, not necessarily connected, porosity of the material and micro and macro cracking induced by mechanical loads, environmental and time dependent effects. Cracks generally interconnect flow paths and decrease the resistance of the material to fluid flow, resulting in an increase of permeability. Consequently, permeability may influence the durability of concrete structures indirectly by controlling the penetration rate of aggressive agents, but also directly if the structure has a confinement role, like nuclear waste storage structures or containment buildings of nuclear power plants for instance.

During their service life, concrete confinement vessels are subjected to different types of loads (mechanical, thermal, chemical, restrained shrinkage, aging etc...). Generally service loads are not significant enough to cause an important degradation of structural concrete [1]. However, with time, the degradation accumulates and may lead to micro-cracking resulting in permeability variations. This contribution aims directly at such confinement structures for which it is critical to evaluate their gas tightness and its evolution with time, both in the case where concrete remains in the pre-peak regime (typically in the normal service life) and also when it might reach locally the post-peak regime, e.g. during integrity tests (or accidents) where an increase of temperature is also expected (from $20{ }^{\circ} \mathrm{C}$ up to $150{ }^{\circ} \mathrm{C}$ in the class of integrity tests considered in this paper). Since such containment vessels are pre-stressed, it is also important to evaluate the influence of 
applied compressive loads on the material permeability. Finally, it should be emphasized that even if the material permeability changes slightly, those variations may be critical as operating threshold of tightness may be overcome, leading to an immediate stop of production. Hence, there is a clear motivation to investigate the variation of the permeability of concrete, even in the pre-peak regime of the mechanical response of concrete where it is usually considered to be negligible compared to observed variations in the post-peak regime.

The evolution of the permeability of concrete may be regarded, on one hand, as a function of diffuse micro-cracking in the material (related to damage) [2,3], and on the other hand as a function of the width, connectivity and tortuosity of newly created flow channels. Relationships between permeability and diffuse damage (micro-cracking) have been derived theoretically. Dormieux and Kondo [3] used homogenisation techniques and similar results were obtained by Chatzigeorgiou et al. [4] based on discrete (lattice) models. Besides, the existence of a percolation threshold has been highlighted by Katz and Thompson and reported in [5]. In the post-peak regime, when a macro-crack has formed in the structure, permeability is governed by Poiseuille flow, crack tortuosity and crack opening (see, e.g. Ref. [6]).

Experimental results on the interaction between permeability and load induced micro-cracks in uniaxial compressive tests are available in the pre-peak regime. A study of Sugyiama et al. [7] on the effect of a compressive stress on permeability of concrete has shown that the increase of permeability becomes significant when the stress level reaches $75-90 \%$ of the ultimate strength for normal-weight and light-weight concretes. Hearn and Lok [8] observed an important increase of air permeability with load induced micro-cracks, occurring at the critical stress level of $71 \%$ of the ultimate axial compressive strength, and corresponding to the development, and then the interconnection of cracks in the mortar matrix. Furthermore, Kermani [9] observed that starting already from $40 \%$ of the ultimate axial compressive strength, the residual water permeability (measured after unloading) increases rapidly, depending on the size or number of micro-cracks. However, Hearn [10] has shown that residual water permeability was insensitive to load induced cracking, because cracks formed below $80 \%$ of the ultimate strength were not likely to form a connected network through the mortar matrix and exhibit partial closing upon unloading. A study of the residual transport properties of concrete, carried out by Picandet et al. [11], has shown that gas permeability increases exponentially with the axial compressive damage (relative stiffness loss) in the pre-peak phase. The phenomenological model of Picandet et al. [11] was correlated with experimental data for low levels of damage (from $0 \%$ to $15 \%$, before the peak load), corresponding to homogenously diffused micro-cracks. In the post-peak regime, when a macro-crack has formed in the structure, Brazilian splitting tests, have emphasized a correlation between the water or gas permeability and the crack width as shown in [12,25]. Discrete parameters such as the crack aperture, the crack length and its orientation enter in the relation.

Besides the applied load, another parameter which influences the permeability of concrete is temperature. Multiple phenomena at the microstructural level of the material take place during an elevation of temperature. Among the most important ones, there is a modification of the moisture content due to capillary water evaporation (up to $120^{\circ} \mathrm{C}$ [24]), chemical dehydration of cement paste due to the loss of bounded water (beyond $105{ }^{\circ} \mathrm{C}$ [13]), thermal expansion, contraction due to phase changes, thermal cracking due to thermal incompatibility, alteration of pores pressure, etc. [14]. The gas permeability is strongly influenced by the moisture content in the material, as shown in Refs. $[15,16]$. The chemical dehydration of the cement paste modifies geometry of the microstructure; concrete hydraulic behaviour is thus affected [17].

According to Gawin et al. [18] a power type relationship between the temperature and the permeability of concrete may be considered. Lion et al. [19] found that a thermal treatment of a mortar leads to an increase of residual porosity and gas permeability, being up to sevenfold its initial value (measured at $25^{\circ} \mathrm{C}$ ) after a treatment at $250^{\circ} \mathrm{C}$. Permeability tests carried out at elevated temperatures have also shown a significant increase of gas permeability at $105^{\circ} \mathrm{C}$ and $200{ }^{\circ} \mathrm{C}$ (threefold increase). The tests performed by Joos and Reinhardt [20] emphasized an increase of water permeability of $13-62 \%$ between $20^{\circ} \mathrm{C}$ and $50{ }^{\circ} \mathrm{C}$, and of $3-55 \%$ between $50{ }^{\circ} \mathrm{C}$ and $80{ }^{\circ} \mathrm{C}$, almost the amount of what could be predicted according to theoretical considerations based on thermodynamics [20].

Existing experimental data provide some correlation between the material mechanical degradation (micro-cracking and macro-cracking) and the permeability of concrete. The same exists for the influence of temperature on permeability of concrete but very little data is available on the coupled temperature and load effects on the permeability of concrete. At the same time, theoretical results or phenomenological formulas exist in both cases but then again, the interaction between the applied load and the temperature on the material permeability lacks experimental validation. The objective of this paper is to provide experimental data from which such validations can be carried out. Because of the specific application aimed at this study, maintenance of nuclear confinement vessels and service life evaluation, we need to consider at the same time variations of permeability due to moderate - diffuse - cracking and variations due to macrocracking. As a matter of fact, it is this first case which is more useful in practical cases and for structural maintenance purposes. The range of temperature is limited to $150{ }^{\circ} \mathrm{C}$ for the same reasons. Despite the observations of Dormieux and Lemarchand [2], reporting that the overall average macroscopic permeability is controlled only by crack density parameter, and is almost independent of the stress level, we wish to investigate at the same time the influence of the applied stress on the material permeability.

Permeability to gas is preferred compared to permeability to water. The main reason is that with water, there is a possibility of migration of fine elements in the smallest pores and also of rehydration of unhydrated cement, resulting in potential autogenous healing of cracked concrete [21], influenced, furthermore, by temperature [22].

The experimental device and the testing procedure are first presented. The results of the experimental study are shown and 
Table 1

Concrete constituents and mix proportions

\begin{tabular}{ll}
\hline Ingredient & Quantity $\left(\mathrm{kg} / \mathrm{m}^{3}\right)$ \\
\hline Limestone gravel, 4-12.5 mm & 939 \\
Sand (Loire), 0-5 mm & 730 \\
Cement CEM II/A 42,5R PM-CP2 & 350 \\
Water & 210 \\
Plasticizer (Glenium 21) & 1.1 \\
Water/cement ratio & 0.60
\end{tabular}

discussed in the next section, where the variations of permeability upon loading (direct measurements during loading) and unloading (measurements after unloading) are presented in the pre-peak and post-peak phases for tests at several temperatures. In the concluding remarks a format for the evolution of permeability with damage and temperature is suggested according to the analysis of the experimental data.

\section{Experimental program}

\subsection{Concrete composition and specimen curing}

For the sake of simplicity, the study is restricted to a dry material whose components are similar to those existing in real nuclear vessels. The mix proportions have been changed in order to obtain a material that is more ductile with a rather standard compressive strength, that could be tested with the frame available in our laboratory. An ordinary concrete of water to cement ratio equal to 0.6 is used. In view of the capacity of the loading frame and of the size of the size of the specimen, the maximum diameter of the limestone gravel is smaller than that of real concrete. Table 1 presents concrete constituents and mix proportions.

Eighteen cylindrical hollow specimens (Fig. 1 (a)) have been cast in metal moulds. A cylindrical borehole was cast in each specimen by placing a metallic bar (diameter of $14 \mathrm{~mm}$ ) in the moulds (see Fig. 1 (b)). All the specimens have been subjected to the same curing and conditioning processes. They were stored in water during 1 month and dried in a ventilated oven initially at $80{ }^{\circ} \mathrm{C}$ (during 1 month), then at $105{ }^{\circ} \mathrm{C}$ down to constant mass. The dry state has been also maintained during the permeability tests whenever possible using the climatic chamber. At a temperature higher than $150{ }^{\circ} \mathrm{C}$, this was not feasible. (a)
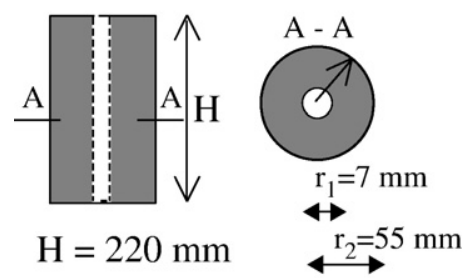

(b)

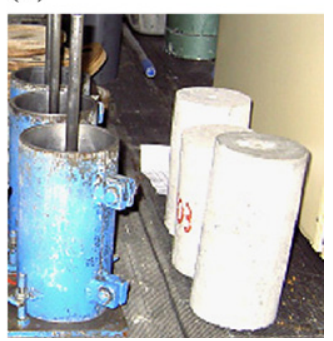

Fig. 1. (a) Geometry of the specimen (b) View of the metal moulds with bars, used for concrete casting.

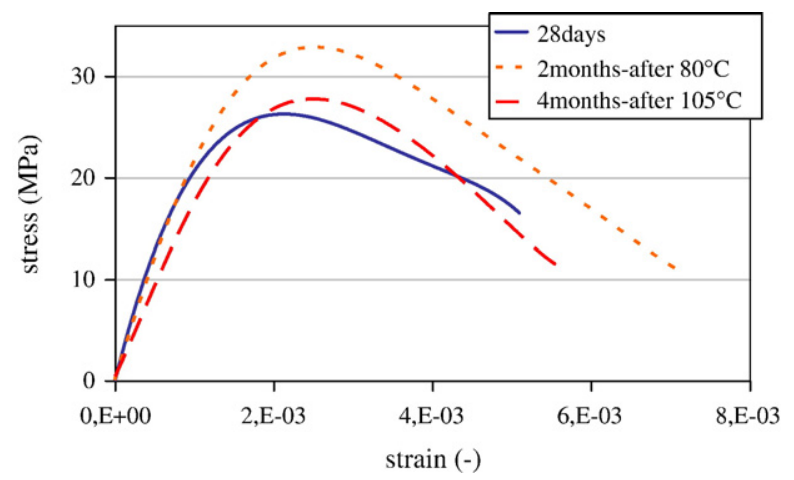

Fig. 2. Stress-axial strain curves of the concrete (test performed at ambient temperature, mean curves).

The average mechanical response of concrete in uniaxial compression is shown in Fig. 2: after the storage in water (at 1 month), after drying at $80{ }^{\circ} \mathrm{C}$ (at 2 months) and $105^{\circ} \mathrm{C}$ (at 4 months). Average mechanical properties are provided in Table 2.

\subsection{Thermal and mechanical loading}

During the mechanical and permeability tests, the specimens are placed in a climatic chamber. This chamber generates and controls temperature and relative humidity. Three levels of temperature are used: $20{ }^{\circ} \mathrm{C}, 105{ }^{\circ} \mathrm{C}$ or $150{ }^{\circ} \mathrm{C}$.

The compression tests are performed with a hydraulic loading frame MTS $500 \mathrm{kN}$ under displacement control. The specimen is placed between two metal platens, designed to apply the compressive force and to enable at the same time the injection of the percolating fluid through the borehole. The axial contraction of the specimen is monitored by the average of the data of three linear variable displacement transducers (LVDT) placed on the circumference of the specimen. The transducers are laid every $120^{\circ}$ intervals to account for any asymmetric longitudinal displacement. The average axial displacement of the central zone of the specimen (length of $105 \mathrm{~mm}$ ) is measured, and converted into an average strain over the measurement base of the LVDTs.

\subsection{Measurements of gas permeability}

A simplified diagram of the experimental device is shown in Fig. 3. Permeability tests are performed for the steady state gas flow in isothermal conditions. An inert gas (nitrogen) is injected

Table 2

Mechanical properties of the concrete (mean values)

\begin{tabular}{|c|c|c|c|}
\hline \multirow[t]{2}{*}{ Property } & \multicolumn{3}{|l|}{ Age of concrete } \\
\hline & $\begin{array}{l}1 \text { month } \\
\text { (after wet cure) }\end{array}$ & $\begin{array}{l}2 \text { months (after } \\
\text { drying at } 80^{\circ} \mathrm{C} \text { ) }\end{array}$ & $\begin{array}{l}4 \text { months (after } \\
\text { drying at } 105^{\circ} \mathrm{C} \text { ) }\end{array}$ \\
\hline $\begin{array}{l}\text { Modulus of elasticity } \\
\text { (GPa) }\end{array}$ & 23 & 22 & 16 \\
\hline Peak stress (MPa) & 26 & 32 & 28 \\
\hline $\begin{array}{l}\text { Axial strain at the } \\
\text { peak (-) }\end{array}$ & $2.2 .10^{-03}$ & $2.5 .10^{-03}$ & $2.6 .10^{-03}$ \\
\hline
\end{tabular}




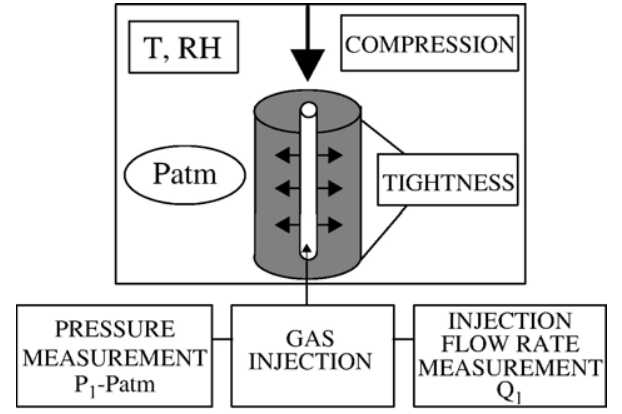

Fig. 3. Simplified diagram of the experimental device.

into the cylindrical borehole through the perforated bottom platen. In order to ensure a radial flow of the gas, the upper and lower faces of the cylindrical specimen are protected by an aluminium film, circular rubber tight joints and silicone grease (see Fig. 4). A relative pressure $\Delta P$ (difference between the injection pressure $P_{\mathrm{i}}$ and the atmospheric pressure $\left.P_{\text {atm }}\right)$ is applied and maintained until gas flow stabilization. The relative pressure and mass flow rate are measured at the upstream of the specimen by the thermal Mass Flow Meter (MFM) which converts the mass flow rate to an equivalent volumetric gas flow rate.

Darcy's law and mass balance equation lead to the determination of an apparent permeability $k_{\mathrm{a}}\left[\mathrm{m}^{2}\right]$. When the injection flow rate $Q_{\mathrm{i}}\left[\mathrm{m}^{3} / \mathrm{s}\right]$ is known, the permeability $k_{\mathrm{a}}\left[\mathrm{m}^{2}\right]$ may be calculated as follows:

$k_{\mathrm{a}}=\frac{Q_{\mathrm{i}} \cdot P_{\mathrm{i}} \cdot \mu \cdot \ln \left(\frac{r_{2}}{r_{1}}\right)}{\pi \cdot H \cdot\left(P_{\mathrm{i}}^{2}-P_{\mathrm{atm}}^{2}\right)}$

where $\mu$ [Pa.s] is the dynamic viscosity of the inert gas used (nitrogen) and $r_{1}[\mathrm{~m}], r_{2}[\mathrm{~m}], H[\mathrm{~m}]$ are the inner radius, outer radius, and the height of the cylindrical specimen respectively. This permeability is relative to the overall gas flow through the material, consisting of the viscous flow and the slip flow. The slip flow appears when the average diameter of the capillaries crossed by gas is of the size of the mean free path of the gas molecules (average distance between collisions).

During mass transport through concrete, the contribution of slip flow in the overall gas flow may be very significant. Hence the permeability, determined for different gas pressures, depends (among other factors due to the microstructure of the material) on the pressure and the temperature, factors which

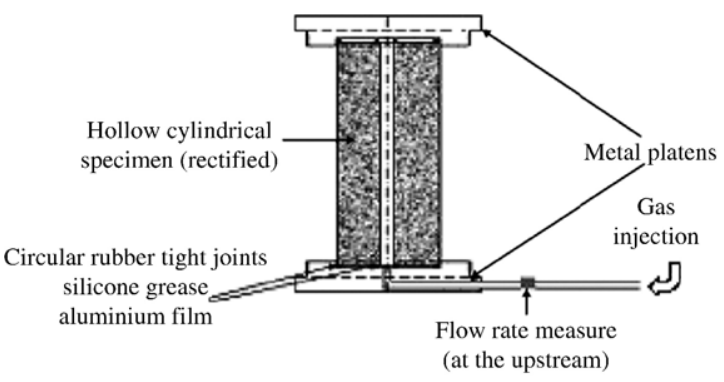

Fig. 4. Schematic representation of the permeability cell. influence the mean free path, which is inversely proportional to the pressure. In order to get an intrinsic permeability in the case of a laminar gas flow, a characteristic of the porous medium solely and being strictly relative to the viscous flow, Klinkenberg or Carman approach may be applied. In this study the relationship due to Klinkenberg [23], presented in Eq. (2), is used:

$k_{\mathrm{a}}=k_{v}\left(1+\frac{\beta}{P_{\mathrm{m}}}\right)$

where $P_{\mathrm{m}}[\mathrm{Pa}]$ corresponds to the average gas pressure, $P_{\mathrm{m}}=$ $\frac{P_{\mathrm{i}}+P_{\text {atm }}}{2}$ and $\beta[\mathrm{Pa}]$ is the Klinkenberg coefficient, a constant which is inversely proportional to the average diameter of the capillaries. The intrinsic permeability $k_{\mathrm{v}}\left[\mathrm{m}^{2}\right]$ is obtained by extrapolating the apparent gas permeability $k_{\mathrm{a}}$ determined at various pressures to the case of an infinite pressure.

\subsection{Testing procedure}

Prior to the test, the specimen is removed from the drying oven and it is left in a desiccator, placed at room temperature $\left(20^{\circ} \mathrm{C}\right)$ for $48 \mathrm{~h}$. After this period, it is instrumented with the displacement transducers (LVDT), and positioned in the permeability cell between the platens of the hydraulic press. This set-up is then enclosed in the climatic chamber. An overall view of the experimental device is shown in Fig. 5.

In the pre-peak phase, the measurements of the apparent permeability are performed for five relative pressures: $0.3,0.25$, $0.20,0.15$, and $0.10 \mathrm{MPa}$. In the post-peak phase, the applied pressures are adapted to the measurable upstream flow rate. The latter is given by one of the three digital thermal Mass Flow Meters (MFM) of ranges: $10-500 \mathrm{ml} / \mathrm{min}, 20-1000 \mathrm{ml} / \mathrm{min}$, and $300-15000 \mathrm{ml} / \mathrm{min}$ respectively. The atmospheric pressure is measured during the test with a digital barometer. A period of 2 to $5 \mathrm{~min}$ approximately, is necessary in order to reach the steady state gas flow. During the test, the applied force, the stroke displacement, the displacements measured from the LVDTs, the gas pressure and mass flow rate through the specimen are recorded. The accuracy of measurement of the apparent

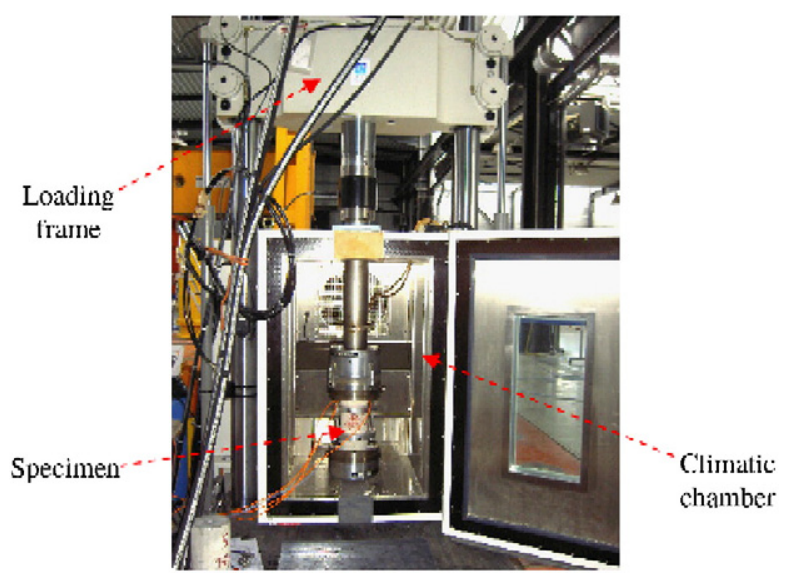

Fig. 5. Overall view of the experimental device. 
permeability is $2 \%$ approximately. The full testing procedure is as follows:

- First, a measurement of the initial permeability of concrete is performed at $20^{\circ} \mathrm{C}$, with an axial compressive load of $4 \mathrm{kN}$, resulting in the compressive stress of $0.4 \mathrm{MPa}$ (negligible stress for this concrete). This load ensures the fitting between the specimen and the load platens. It is needed for ensuring the tightness of the permeability cell (radial flow only). This initial permeability is subsequently used as a reference value in forthcoming comparisons.

- Then, the required temperature is applied $\left(20{ }^{\circ} \mathrm{C}, 105^{\circ} \mathrm{C}\right.$ or $150{ }^{\circ} \mathrm{C}$ ). During heating at a constant rate of $10{ }^{\circ} \mathrm{C} / \mathrm{h}$, the compressive load of $4 \mathrm{kN}$ is kept. A stabilization period of temperature through the material is needed, thus permeability tests start after $60 \mathrm{~h}$, under a constant temperature. Prior to that, the permeability is measured again in order to obtain the effect of the temperature.

- Afterwards, the specimen is loaded with a displacement rate of $0.02 \mathrm{~mm} / \mathrm{min}$ up to the required load level. Load levels correspond to $20,40,60,80,85$ and $90 \%$ of the estimated peak stress in the pre-peak regime, while close to the peak and in the post-peak phase each load level corresponds to an increase of axial strain of $0.3 \mathrm{~mm} / \mathrm{m}$. Each load level is maintained during $30 \mathrm{~min}$ in order to allow for the determination of the gas permeability. For each load level, once the permeability under load is measured, the specimen is unloaded down to $4 \mathrm{kN}$ and the permeability of the unloaded specimen is measured.

Time dependent effects (creep or relaxation) are not significant during the pre-peak phase. Nevertheless, close to the peak and beyond, the flow rate measurements are affected by load relaxation. In this case, the time needed to reach a steady state flow rate raises and corresponds to the stabilization of cracks propagation for the imposed displacement, which is kept constant. All the results presented below refer to the values of permeability obtained with four tests per temperature.

\section{Results and discussion}

The initial permeability of the concrete tested (prepared with three batches) varies between $6 \cdot 10^{-17} \mathrm{~m}^{2}$ and $12 \cdot 10^{-17} \mathrm{~m}^{2}$. This variation is relatively small and illustrates the good reproducibility of the material on one hand. On the other hand, these values are overestimated, compared to usual concrete which is never completely dry, because of moisture and drying shrinkage cracking effects $[10,15,16]$. Nevertheless, all the specimens considered here possess the same initial microstructural state. The initial values of the permeability are employed as references in forthcoming comparisons.

In our experiments, concrete revealed a consistent temperature dependent behaviour, getting more and more brittle with temperature and tending to brittle failure (for some other examples of such an effect see, e.g., Ref. [24]). The typical stress-axial strain responses recorded during the tests carried out at $20^{\circ} \mathrm{C}, 105^{\circ} \mathrm{C}$ and $150^{\circ} \mathrm{C}$ are presented in Fig. 6 (a), (b) (a)

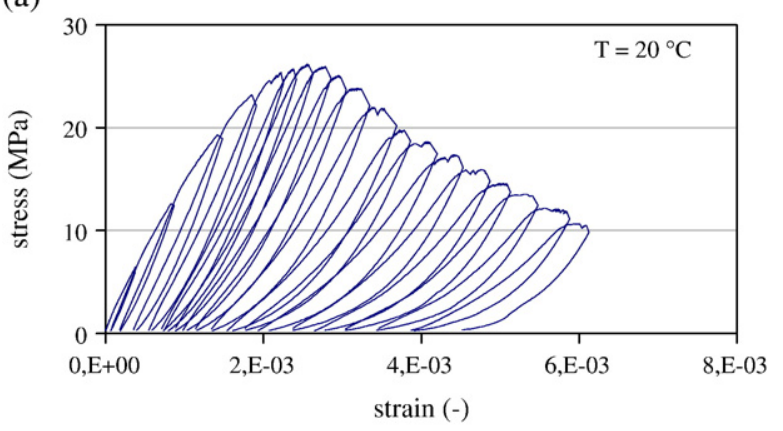

(b)
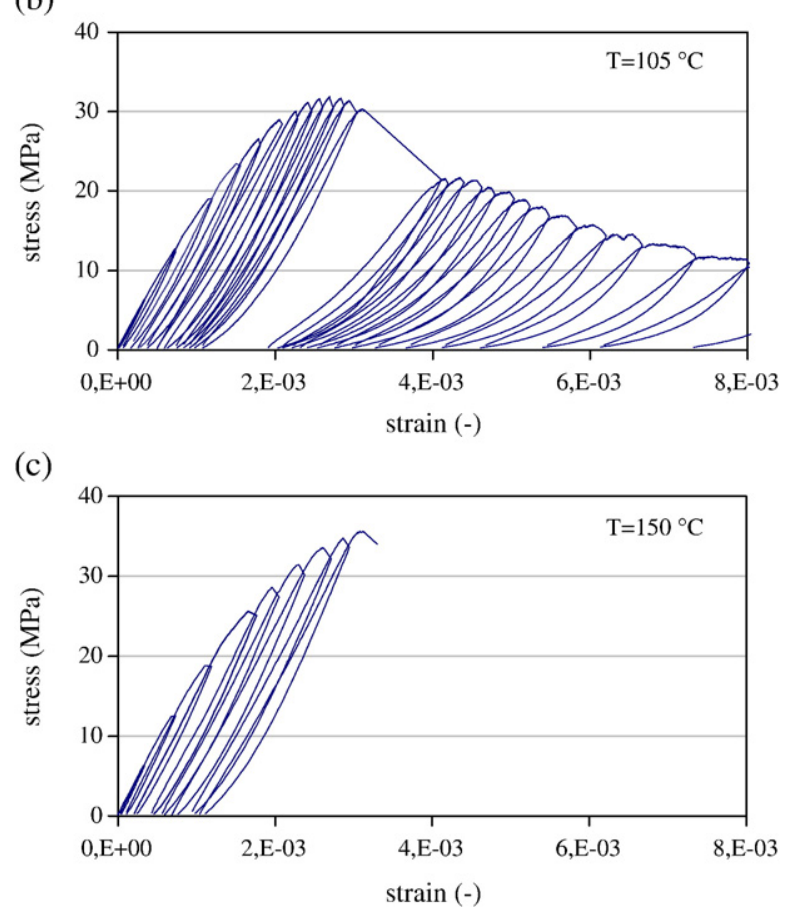

Fig. 6. Typical stress-strain relation at (a) $20^{\circ} \mathrm{C}$ (b) $105^{\circ} \mathrm{C}$ (c) $150{ }^{\circ} \mathrm{C}$.

and (c), respectively. For the tests performed at $20{ }^{\circ} \mathrm{C}$ and $105{ }^{\circ} \mathrm{C}$, the response remains quite ductile and permeability measurements in the post-peak phase are available. At $150{ }^{\circ} \mathrm{C}$, however, the mechanical response becomes brittle; this restricts permeability measurements in the post-peak phase. Since the specimen fails suddenly, it is rather difficult to control the load in order to perform several measurements of permeability at different stages in the post-peak phase.

\subsection{Permeability during loading and after unloading}

The results presented in Fig. 7 (a), (b) and (c) show the permeability measured under applied load and after unloading for different maximum applied stress levels at $20{ }^{\circ} \mathrm{C}, 105{ }^{\circ} \mathrm{C}$ and $150{ }^{\circ} \mathrm{C}$ (only two tests per temperature are presented for the sake of clarity of the plots), respectively. It can be noticed that for low and intermediate maximum applied stress levels, the permeability measured after unloading is slightly greater than during loading. For high maximum applied stress levels, beyond a threshold corresponding to $80 \%$ of the peak stress at 
(a)

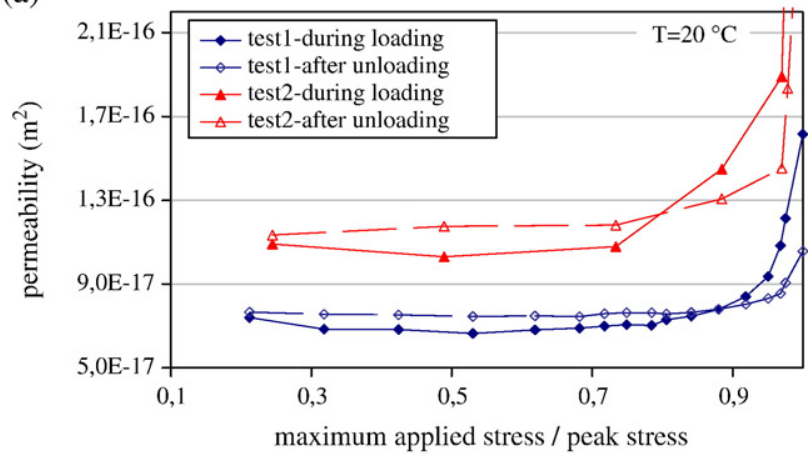

(b)

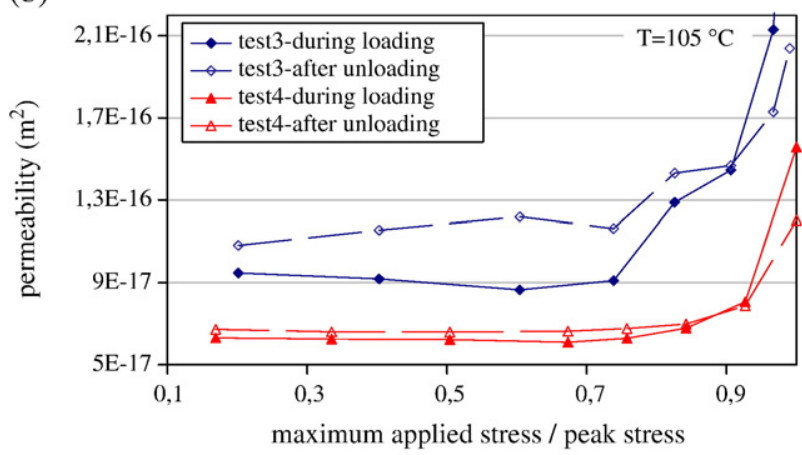

(c)

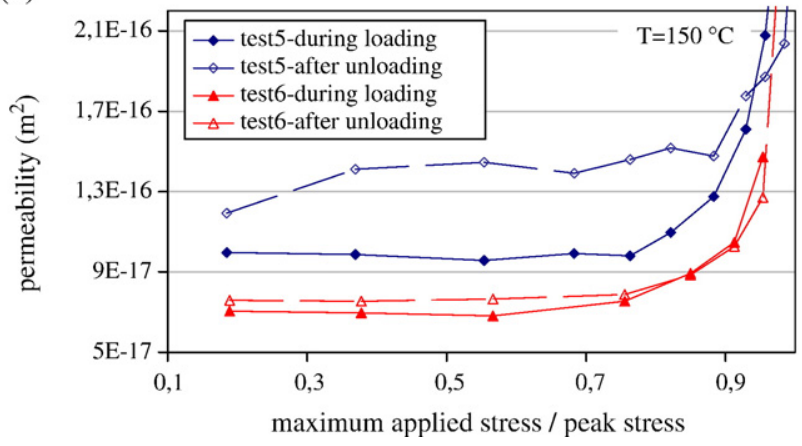

Fig. 7. Loading and unloading intrinsic permeability vs maximum applied relative stress at (a) $20{ }^{\circ} \mathrm{C}$ (b) $105^{\circ} \mathrm{C}$ (c) $150{ }^{\circ} \mathrm{C}$.

$20{ }^{\circ} \mathrm{C}$, and close to $90 \%$ at $105^{\circ} \mathrm{C}$ and $150{ }^{\circ} \mathrm{C}$, the inverse trend is observed. This effect is noticeable not only on the intrinsic permeability (calculated from Klinkenberg relationship), but also on the apparent permeability (Fig. 8). Apparent permeabilities, measured during loading for a moderate stress level (19\% of the peak stress) at any average pressure of gas injection, are lower than after unloading; while for a significant stress level (91\% of the peak stress) the result is opposite.

The ratio of loading to unloading permeabilities varies with the applied stress level and temperature. In the strain space (longitudinal strain measured on the specimen), it may be represented by a function which reaches the values lower than one in the early pre-peak phase, reaches a maximum in early post-peak phase for a relative strain equal to 1.1-1.2 (maximum load induced strain to peak strain), and tends to become a constant further in the post-peak regime (the two permeabilities are equal). This relation is plotted in Fig. 9 for the three tested temperatures.

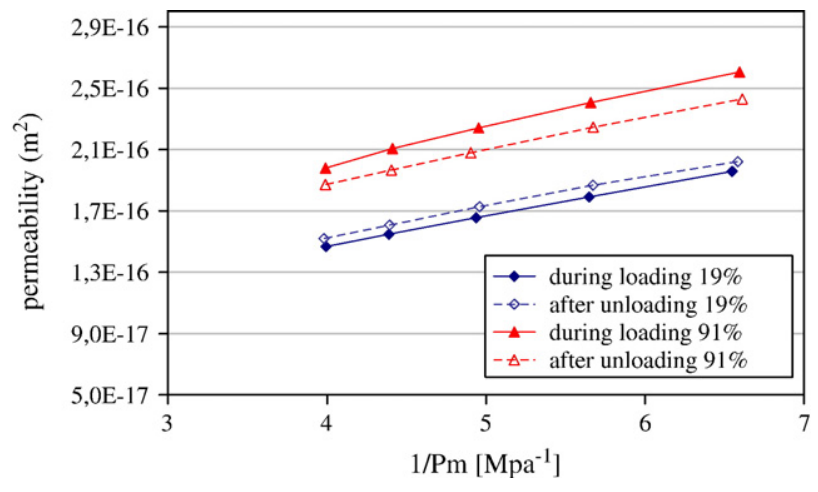

Fig. 8. Effects of loading and unloading and of the mean gas pressure on the apparent permeability values (typical result, at $20^{\circ} \mathrm{C}$ ).

The decrease of permeability is observed in the quasi-elastic phase of concrete behaviour. As the behaviour is reversible in this phase, only the volume of the flow channels (pores and micro-cracks) is affected and no additional connectivity is created. Probably, the low compressive stress levels act on the initial porosity and micro-cracking by squeezing it (volume contraction). The diameter of perpendicular to the direction of the loading lengthened (due to Poisson's effect) flow channels decreases and consequently, even at micro-structural level, where permeability is governed by Poiseuille's law, permeability perpendicular to the direction of the loading should decrease. In contrary, due to Poisson's effects, the diameter of parallel to the direction of the loading flow channels may slightly increase but, as the mean volumetric behaviour is strictly contracting in this phase, a change in permeability parallel to the direction of the loading should remain rather small. In the case of the present tests, unloading generates the opposite effect and thus the permeability increases (the behaviour is reversible). Till approximately $70-80 \%$ of the peak stress, the permeability measured after unloading remains quasi-constant, while the permeability measured during loading slightly varies at $20^{\circ} \mathrm{C}$, $105{ }^{\circ} \mathrm{C}$ and $150{ }^{\circ} \mathrm{C}$ (Fig. 7 (a), (b), (c)). Possible micro-crack formation is compensated by the closure of existing pores and the resulting effect on the permeability is a slight decrease. Upon unloading, cracks induced by the applied load may close while existing pores or cracks open again, with an increase of

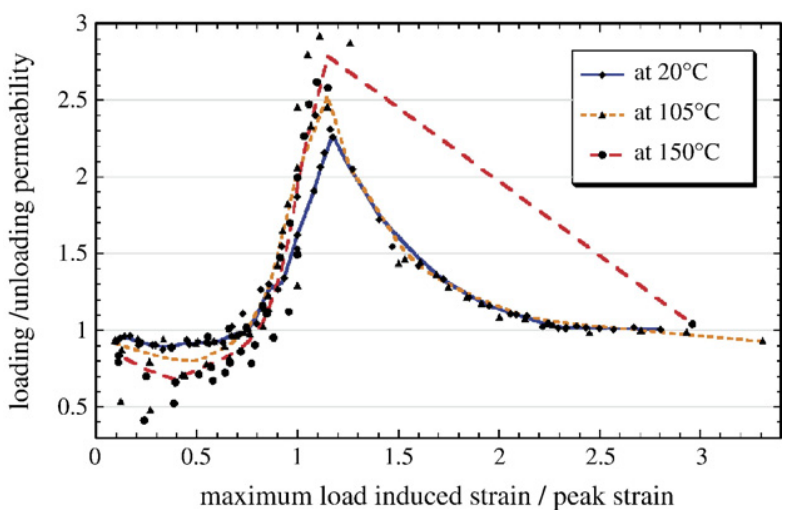

Fig. 9. Loading to unloading intrinsic permeability ratio vs applied relative strain (lines correspond to smooth fit of experimental data). 


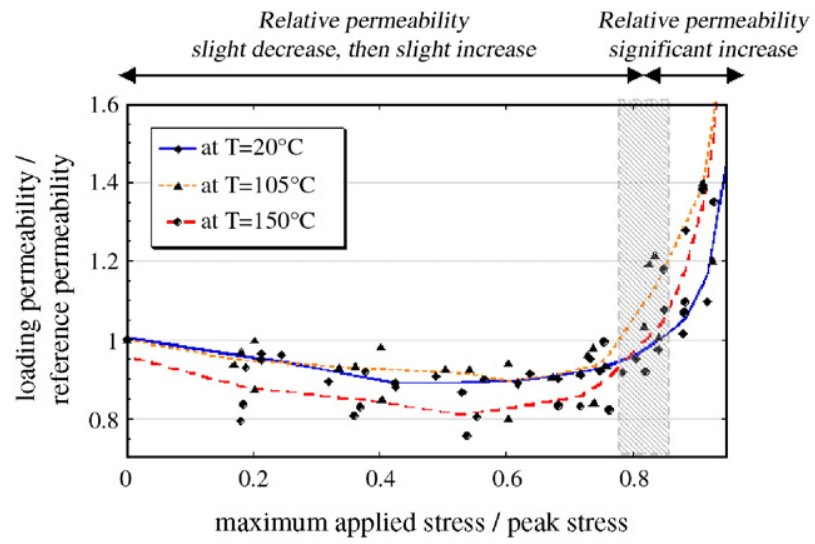

Fig. 10. Variation of intrinsic permeability values with loading for tested temperatures (lines correspond to smooth fit of experimental data).

the permeability. Beyond these stress levels, permeability measured during loading exceeds the values revealed after unloading. The amount of micro-crack formed is enough in order to compensate effect of closure of the initial microstructure. Consequently, the permeability measured during loading reaches greater values than after unloading.

\subsection{Pre-peak phase}

\subsubsection{Evolution of permeability with mechanical loading}

In the pre-peak phase, for each temperature, the characteristic phases of relative permeability evolution (permeability at temperature of 20,105 or $150{ }^{\circ} \mathrm{C}$ over the reference permeability at temperature of 20,105 or $150^{\circ} \mathrm{C}$, respectively) with maximum applied compressive stress can be distinguished, as depicted in Fig. 10. Here, results consider the intrinsic permeability measured during loading only.

Under the action of low and intermediate stress levels, corresponding to $40-60 \%$ of the peak stress, the permeability tends to decrease slightly. Beyond this level, the permeability increases, first very slightly, then significantly (from $80 \%$ of the peak stress), with the most important rate for the test carried out at $150{ }^{\circ} \mathrm{C}$.

The evolution of the relative permeability during loading, joining up with the results presented in the previous section, may be related to the volumetric behaviour of concrete under uniaxial compression. The typical volumetric behaviour is presented in Fig. 11. It could be considered, that the decrease of the permeability for low maximum applied stress levels (Fig. $10)$ is due to the contracting volumetric behaviour under uniaxial compressive loading. At $75-85 \%$ of the peak stress, the permeability recovers its initial value and then starts to increase (see also Ref. [7]). When the volumetric response becomes dilating, the permeability increases, first slightly, due to the development of homogenously diffused micro-cracks through the cement paste, then significantly (from $80 \%$ of the peak stress) due to the micro-cracks coalescence (as reported in $[7,8,11])$. This critical stress level of $80 \%$, considered as a threshold of significant permeability increase, corresponds to the contracting-dilating transition of the volumetric response of

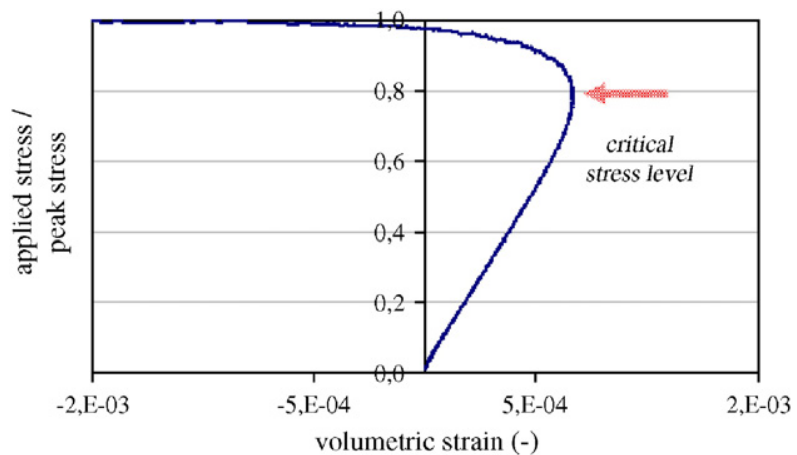

Fig. 11. Typical stress-volumetric strain response (arrow indicates critical stress level).

the material [7], as presented in Fig. 11 (arrow indicates the critical stress level of permeability increase).

\subsubsection{Evolution of permeability with temperature}

An increase of the relative permeability with temperature is observed in Fig. 12 (a) and (b) (permeability measured at $20^{\circ} \mathrm{C}$, $105{ }^{\circ} \mathrm{C}$ or $150{ }^{\circ} \mathrm{C}$ over the initial permeability measured at $20^{\circ} \mathrm{C}$ ). The results presented in Fig. 12 (a) highlight a slight relative permeability increase with temperature without mechanical loading. This increase is greater with the applied load as shown in Fig. 12 (b). Several reasons for this variation of permeability with temperature might be considered. Between $20^{\circ} \mathrm{C}$ and $150-200{ }^{\circ} \mathrm{C}$, thermal expansion of the cement paste

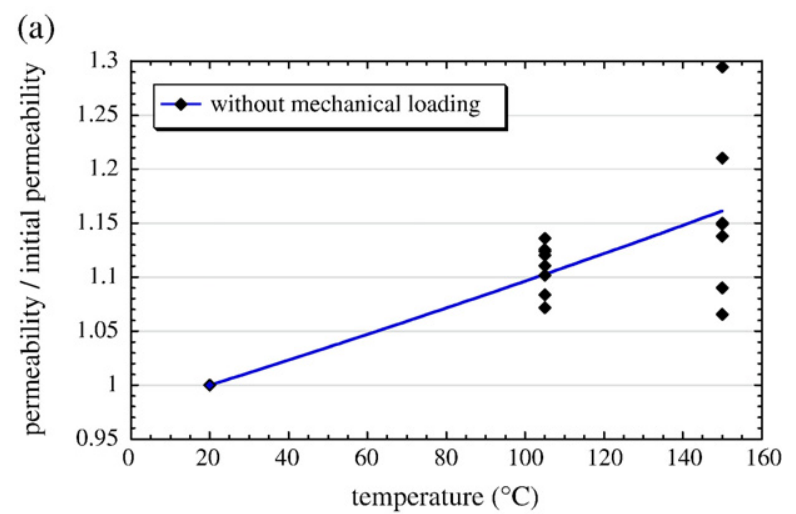

(b)

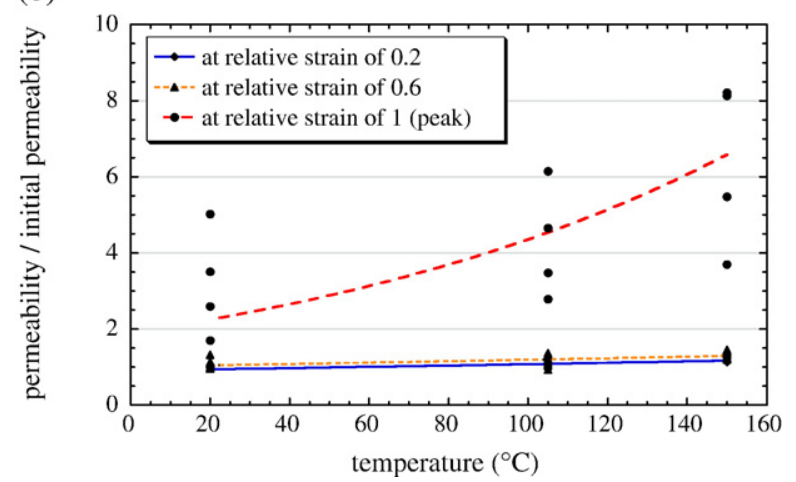

Fig. 12. Variation of intrinsic permeability under temperature (lines correspond to smooth fit of experimental data) (a) without mechanical loading (b) with mechanical loading. 

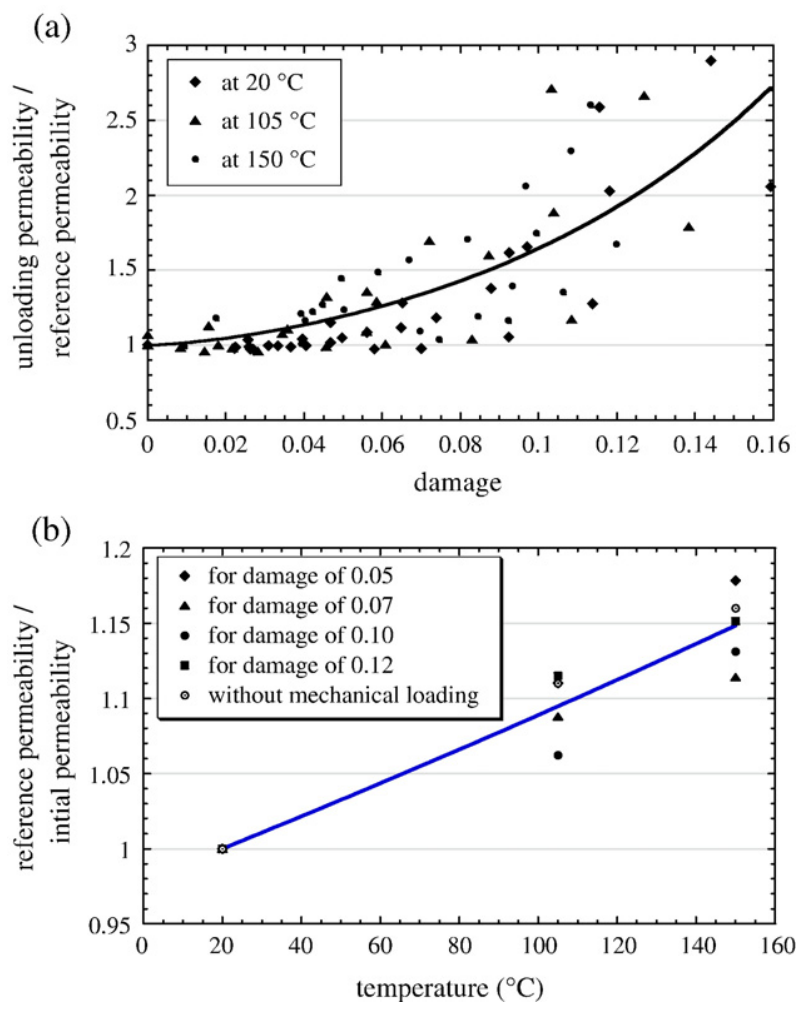

Fig. 13. (a) Variation of relative to mechanical state intrinsic unloading permeability with damage for the three tested temperatures (b) Variation of relative to temperature intrinsic permeability with temperature for different damage levels (curves correspond to exponential fit of experimental data).

and aggregates takes place [17,19]. Because the thermal expansion coefficients are different for each constituent of concrete, micro-cracks should appear at the cement pasteaggregate interface. Beyond $150-200{ }^{\circ} \mathrm{C}$, the expansion of the aggregates is limited by the shrinkage of the cement paste, what results in cracking through the latter. In this range of temperatures (already beyond $105{ }^{\circ} \mathrm{C}$, according to [13]) the cement paste shrinks due to dehydration. Therefore, chemical bonds, forming the CSH gel, start to break down. Hydrated products transform into anhydrous product and free water evaporates during further heating and creates new channels accessible for the gas flow. Furthermore, porosity and pores distribution change, due to the exposure to high temperatures, has already been emphasized by experimental evidences, as reported in $[17,26]$.

In our study, the increase of relative permeability observed at $105{ }^{\circ} \mathrm{C}$ compared to $20{ }^{\circ} \mathrm{C}$ cannot be related to thermal microcracking. This temperature has already been experienced by all the specimens during drying. Since moisture effects cannot occur, one remaining cause is the widening of pores through relative thermal expansion of the (heterogeneous) material. In order to verify this assumption, the microstructure of the material needs to be scrutinised. One useful indication, serving as a first step in such a study, is the analysis of the variation of the Klinkenberg coefficient $\beta[\mathrm{Pa}]$. It is inversely proportional to the average diameter of the pores and thus it may be considered as an indicator of the fineness of the porosity in the material [25]. A decrease of $\beta$ (of up to $10 \%$ ) is observed between $20{ }^{\circ} \mathrm{C}$ and $105{ }^{\circ} \mathrm{C}$. This decrease is related to the increase in the pore size, which takes place due to the thermal expansion of the porous material. Consequently, the intrinsic permeability increases most probably due to the pores widening between $20^{\circ} \mathrm{C}$ and $105^{\circ} \mathrm{C}$.

The increase of permeability at $150^{\circ} \mathrm{C}$, compared to the two other levels of temperature has to be likewise related to pores widening. However, a decrease of $\beta$ has not been observed in the tests; on the contrary, an increase (of $30 \%$ ) of $\beta$ has been computed. We suppose that the contribution of very fine pores, created by the thermal treatment at $150{ }^{\circ} \mathrm{C}$, is relatively more important than pores widening at this temperature.

\subsubsection{Evolution of permeability with damage and temperature- interaction law}

Apart from the separate effect of the mechanical load and temperature on the permeability, some information can be obtained as far as the coupled effect of load and temperature on permeability is concerned.

Following the analysis by Picandet et al. [11], it is more consistent, in the pre-peak phase to record the evolution of the permeability with damage instead of the strain or stress. In order to analyse the effect of the applied load on permeability, we follow here the same procedure and compute damage from the variation of the unloading stiffness recorded on the mechanical response of the specimen. The result is shown in Fig. 13 (a). On this plot, we have the permeability evaluated after unloading as a function of damage $d$ defined as $d=\frac{E_{0}-E_{\text {unloading }}}{E_{0}}$ where $E_{0}$ is the initial Young's modulus of the material and $E_{\text {unloading }}$ is the unloading modulus. Same as in Ref. [11], the plot exhibits some dispersion due to the evaluation of the unloading slopes. Still, the agreement for all the temperatures seems correct. One may say that the evolution of the permeability due to the applied load for the three temperatures tested falls on the same master curve. Note that we have considered in this figure the permeability measured after unloading instead of the permeability measured under load, since it is expected that for the permeability measured under load, some load effect could be accounted for,

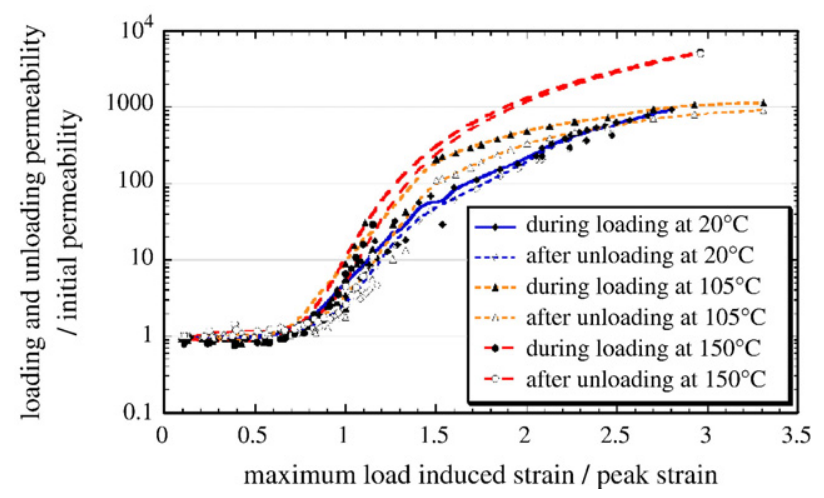

Fig. 14. Variation of relative intrinsic permeability with maximum applied relative strain for the three tested temperatures. Measurements carried out at temperature, during loading and after unloading (lines correspond to smooth fit of experimental data). 
or possibly neglected in the pre-peak phase (for conservative safety reasons, the decrease of permeability may be neglected).

The effect of the temperature on the permeability, measured with applied mechanical load, is shown in Fig. 13 (b) for some damage levels. We observe that the evolution of the permeability with the temperature is almost the same for any state of damage considered.

Therefore, one may possibly say that the overall evolution of the permeability follows a multiplicative format: $k=f$ (damage) $g$ (temperature). The increase of permeability due to temperature and damage is the product of two functions ( $f$ and $g$ ) which reflect each contribution separately. Our experimental results are also consistent with the formula proposed by Gawin and coworkers [18].

\subsection{Peak and post-peak phases}

The results presented in Fig. 14 show the complete evolution of the relative permeability during loading and after unloading with the maximum applied relative strain for the three tested temperatures. It turns out that at the peak (relative strain equal to 1 ), the permeability becomes ten time its initial value approximately, if measured during loading at elevated temperatures $\left(105^{\circ} \mathrm{C}\right.$ and $150{ }^{\circ} \mathrm{C}$ ), and up to five times its initial value, if measured at $20^{\circ} \mathrm{C}$. Up to the peak, the variation of the relative permeability is quite moderate in comparison to the post-peak phase.

The change of the permeability becomes greater with the increase of temperature. It can be explained by the fact that concrete becomes more brittle with temperature. Diffuse microcracking is less developed and major through-cracks, in which fluid flow resistance is very small compared to that of the uncracked material, appear sooner. It is also observed that the permeability growth rate increases with temperature. At $105^{\circ} \mathrm{C}$, although this temperature was applied to all the specimens during drying, the increase of the rate of permeability is greater than at $20{ }^{\circ} \mathrm{C}$. For the tests carried out at $150{ }^{\circ} \mathrm{C}$, due to the brittleness of concrete, permeability could not be measured continuously in the post-peak phase. The experimental results presented in Fig. 14 for $150{ }^{\circ} \mathrm{C}$ in the post-peak regime, correspond to measurements at failure, and we have extrapolated the results to a smooth curve between the peak and failure, assuming that its shape should not be very different from what is observed at other temperatures.

Three regimes of variation of permeability, as a function of the strain of the specimen, are observed for all tested temperatures in Fig. 14: the first one (up to a relative strain of 0.9 ), where the permeability varies relatively slightly, the second one (for a relative strain between 0.9 and 1.4), where the permeability increases rapidly and the third one, which is characterized by a steady and slower rate than the latter. These observations are in agreement with the experimental results obtained by Gérard [27] and Wang et al. [12]. The first regime corresponds probably to the fluid percolation through both the pores and diffused micro-cracks in concrete (permeability increase governed by diffused damage $[3,4,11]$ ), the second one corresponds to the fluid flow through interconnected micro- cracks which initialise cracks formation, while the third one is probably related to the localized fluid flow through the cracks only (Poiseuille flow).

\section{Concluding remarks}

The results reported in this study can be summarised as follows:

- In the pre-peak phase, several regimes may be distinguished as far as the evolution of permeability is concerned. The first one corresponds to a slight decrease of permeability, due to the compaction effect of compressive loading on the material. Then, a quite moderate increase of permeability is observed. At the peak, an increase of permeability up to one order of magnitude occurs for elevated temperatures $\left(105^{\circ} \mathrm{C}\right.$ and $150^{\circ} \mathrm{C}$ ), while at $20^{\circ} \mathrm{C}$ a fivefold increase is observed.

- In the post-peak phase an important growth of permeability takes place due to the crack widths growth under compressive loading. The change of permeability seems to be greater with the increase of temperature.

- The effect of the applied stress is first a decrease of the permeability. This effect can be neglected in structural analyses; at least it should be conservative to do so for structural elements loaded in compression (such as confinement vessels). As micro-cracking develops, the reverse is observed and the permeability under load becomes greater than upon unloading. Furthermore, micro-cracks do not close entirely upon stress reversal and the permeability during unloading increases.

- The permeability increases with the temperature. At $105{ }^{\circ} \mathrm{C}$ (temperature already experienced by the material previously) it is due to the pore widening due to thermal expansion of concrete porous material. At $150{ }^{\circ} \mathrm{C}$, where the increase is much more important, it is due to pore widening and temperature induced micro-cracking.

Finally, the experimental results seem to agree with the format of coupled evolution of the permeability due to damage and temperature: $k=f$ (damage) $g$ (temperature), assumed by Gawin et al. [18]. Obviously, this is not a general proof that the above relationship should hold for any concrete, temperature or damage, but experimental data are not in contradiction with it. Further studies with different concretes and a wider range of temperature are needed. There is, in particular, a need for similar works concerning high-performance concrete which is more brittle that ordinary concrete, since it is used for some confinement vessels. Concerning the relationship between permeability and damage, however, Picandet et al. [11] have observed similar permeability increases for an ordinary and a high-performance concrete for a moderate compressive damage, in the pre-peak phase.

\section{Acknowledgements}

Financial supports from the network on Degradation and Instabilities in Geomaterials with Application to Hazards Mitigation (DIGA), contract HPRN-CT-2002-00220 with the 
European Commission and from the partnership between EDF and the R \& DO group are gratefully acknowledged. [K.S.]

\section{References}

[1] W.E. Norris, D.J. Naus, H.L. Graves, Inspection of nuclear power plant containment structures, Nuclear Engineering and Design 192 (1999) 303-329.

[2] L. Dormieux, E. Lemarchand, Homogenization approach of advection and diffusion in cracked porous material, Journal of Engineering Mechanics 127 (2001) 1267-1274.

[3] L. Dormieux, D. Kondo, Approche micromécanique du couplage perméabilité-endommagement, Comptes Rendus. Mecanique 332 (2004) 135-140 (in french).

[4] G. Chatzigeorgiou, V. Picandet, A. Khelidj, G. Pijaudier-Cabot, Coupling between progressive damage and permeability of concrete: analysis with a discrete model, International Journal for Numerical and Analytical Methods in Geomechanics 29 (2005) 1005-1018.

[5] D. Breysse, B. Gérard, Modelling of permeability in cement-based materials: part 1-uncracked medium, Cement and Concrete Research 27 (1997) 761-775.

[6] F.A.L. Dullien, Porous media, Fluid Transport and Pore Structure, Academic Press, 1979.

[7] T. Sugiyama, T.W. Bremner, T.A. Holm, Effect of stress on gas permeability in concrete, ACI Materials Journal 93 (1996) 443-450.

[8] N. Hearn, G. Lok, Measurement of permeability under uniaxial compression-A test method, ACI Materials Journal 95 (1998) 691-694.

[9] A. Kermani, Stressed concrete. Permeability of stressed concrete, Building Research and Information 19 (1991) 360-366.

[10] N. Hearn, Effect of shrinkage and load-induced cracking on water permeability of concrete, ACI Materials Journal 96 (1999) 234-241.

[11] V. Picandet, A. Khelidj, G. Bastian, Effect of axial compressive damage on gas permeability of ordinary and high-performance concrete, Cement and Concrete Research 31 (2001) 1525-1532.

[12] K. Wang, D.C. Jansen, S.P. Shah, A.F. Karr, Permeability study of cracked concrete, Cement and Concrete Research 27 (1997) 381-393.

[13] Z.P. Bazant, F.H. Whittmann, Creep and Shrinkage in Concrete Structures, John Wiley \& Sons, 1982.

[14] B.M. Luccioni, M.I. Figueroa, R.F. Danesi, Thermo-mechanic model for concrete exposed to elevated temperatures, Engineering Structures 25 (2002) 729-742.
[15] M.A. Sanjuan, R. Munoz-Martialay, Oven-drying as a preconditioning method for air permeability test on concrete, Materials Letters 27 (1996) 263-268.

[16] D.R. Gardner, R.J. Lark, B. Barr, The effect of conditioning to a predetermined weight loss on the permeability of concrete, Construction and Building Materials 21 (2007) 83-89.

[17] M. Tsimbrovska, Dégradation des bétons à hautes performances soumis à des températures élevées. Evolution de la perméabilité en liaison avec la microstructure, Thèse de doctorat $(\mathrm{PhD}$ Thesis in French), Université Grenoble 1, 1998.

[18] D. Gawin, C.E. Majorana, B.A. Schrefler, Numerical analysis of hygrothermal behaviour and damage of concrete at high temperature, Mechanics of Cohesive-Frictional Materials 4 (1999) 37-74.

[19] M. Lion, F. Skoczylas, Z. Lafhaj, M. Sersar, Experimental study on a mortar. Temperature effects on porosity and permeability. Residual properties or direct measurements under temperature, Cement and Concrete Research 35 (2005) 1937-1942.

[20] M. Joos, H.W. Reinhardt, Permeability and diffusivity of concrete as function of temperature, Cement and Concrete Research 32 (2002) 1497-1504.

[21] C. Edvardsen, Water permeability and autogeneous healing of cracks in concrete, ACI Materials Journal 96 (1996) 448-454.

[22] H.W. Reinhardt, M. Joos, Permeability and self-healing of cracked concrete as a function of temperature and crack width, Cement and Concrete Research 33 (2003) 981-985.

[23] L.J. Klinkenberg, The permeability of porous media to liquids and gases, Drilling and Production Practice, American Petroleum Institute, 1941, pp. 200-213.

[24] A., Noumowé,Effet de hautes temperatures $\left(20-600^{\circ} \mathrm{C}\right)$ sur le béton. Cas particulier du béton à hautes performance, Thèse de doctorat $(\mathrm{PhD}$ Thesis in French), INSA Lyon, 1995.

[25] V. Picandet, Influence d'un endommagement mécanique sur la perméabilité et sur la diffusivité hydrique des bétons, Thèse de doctorat $(\mathrm{PhD}$ Thesis in French), Université de Nantes, 2001.

[26] S. Dal Pont, A. Erlacher, Numerical and experimental analysis of chemical dehydration, heat and mass transfers in a concrete hollow cylinder submitted to high temperatures, International Journal of Heat and Mass Transfer 47 (2004) 135-147.

[27] B. Gérard, Contribution des couplages mécanique chimie transfert dans la tenue à long terme des ouvrages de stockage de déchets radioactifs, Thèse de doctorat (PhD Thesis in French), ENS Cachan, 1996. 